\title{
Genomic insights into a robust gamma-aminobutyric acid-producer Lactobacillus brevis CD0817
}

\author{
Dandan Gao ${ }^{1 \dagger}$, Kunpeng Chang ${ }^{2,3 \dagger}$, Gongtao Ding ${ }^{1}$, Hongjing Wu${ }^{4}$, Yuanhong Chen ${ }^{2,3}$, Mengya Jia ${ }^{2,3}$, \\ Xiaohua Liu ${ }^{3}$, Shuixing Wang ${ }^{3}$, Yuyuan $\mathrm{Jin}^{3}$, Hao Pan ${ }^{3}$ and Haixing Li $\mathrm{Li}^{1,2,3^{*}}$
}

\begin{abstract}
Lactobacillus brevis CD0817, a strain isolated from a healthy adult gut, was currently the most efficient lactic acid bacterial cell factory for gamma-aminobutyric acid. In this study, the complete genome sequence of CD0817 was determined and compared with some related L. brevis genomes. The CD0817 genome consists of one 2,990,570-bp chromosome and four plasmids. The comparative genomic and phylogenetic analysis revealed that L. brevis CD0817 was not very conserved with low GABA-producing L. brevis strains. A significant divergence was that CD0817 harbors only the gadCA operon whereas the low GABA-producing L. brevis strains contain the operon and gadB. The gadB seemed to only marginally contribute to the accumulation of GABA. The high GABA production ability of CD0817 may be associated with its extraordinary genome.
\end{abstract}

Keywords: Lactobacillus brevis CD0817, Complete genome sequence, Comparative genomics analysis, Gammaaminobutyric acid, Glutamic acid decarboxylase

\section{Introduction}

Gamma-aminobutyric acid (GABA), a four-carbon nonprotein amino acid diffusely distributed in nature, is the major inhibitory neurotransmitter in the mammalian central nervous system ( $\mathrm{Li}$ and Cao 2010). GABA has been widely applied in pharmaceutical, food and feed industries, due to its important physiological functions, such as anti-anxiety (Wong et al. 2003), hypotensive (Inoue et al. 2003), and diuretic effects (Nikmaram et al. 2017). Over the past three decades, the bio-manufacture of GABA by using lactic acid bacteria (LAB) has been vigorously pursued due to the fact that $\mathrm{LAB}$ are generally regarded as safe ( $\mathrm{Li}$ and Cao 2010). Numerous LAB strains, notably lactobacilli belonging to $L$. brevis (Wu et al. 2015), L. plantarum (Siragusa et al. 2007),

*Correspondence: hxli@ncu.edu.cn

†Dandan Gao and Kunpeng Chang contributed equally to this work

1 Biomedical Research Center, College of Life Sciences and Engineering, Northwest Minzu University, Lanzhou 730030, Gansu, People's Republic of China

Full list of author information is available at the end of the article
L. paracasei (Komatsuzaki et al. 2005) and L. buchneri (Zhao et al. 2015) have been applied to biosynthesize GABA.

Glutamic acid decarboxylase (GAD) system (namely GABA synthesizer) comprising glutamate/GABA antiporter (encoded by $g a d C$ ) and GAD enzyme (encoded by $\operatorname{gadA}$ or $\operatorname{gadB}$ ) is responsible for the synthesis of GABA in microbial cells: glutamate is transported into a cell through the antiporter, subsequently decarboxylation occurs, finally the decarboxylated product is exported from the cell by the antiporter (Small and Waterman 1998). Of the three genes, gadCA form an operon while $\operatorname{gadB}$ is separate and far from the operon circa $1.7 \mathrm{Mb}$ in a L. brevis genome (Li et al. 2013).

It is intriguing that low GABA-producing L. brevis strains possessing an identical GAD system exhibited entirely different GABA-synthesizing ability ( $\mathrm{Li}$ and Cao 2010). It was therefore presumed that the formation of GABA may also be associated with cell physiological status essentially determined by genetic information. Data at genome level may help us to understand the causes regarding this discrepancy in GABA yield. However, of all 
the reported GABA-producing L. brevis strains, no more than the genome of L. brevis NPS-QW-145 is currently available (Wu et al. 2015; Wu and Shah 2015); on the other hand, only strain NPS-QW-145 has been clearly demonstrated to generate GABA among the several genome-sequenced $L$. brevis strains.

Recently, a strain L. brevis CD0817 with the highest known GABA production ( $252 \mathrm{~g} / \mathrm{L})$ among LAB strains was screened from the gut of a healthy adult (Chen et al. 2019). Herein, the complete genome sequence of CD0817 was reported and compared with some other completely sequenced $L$. brevis genomes; and the GAD system of CD0817 was highlighted. This work would enrich the genome database of GABA-producing LAB, and thus may help us to seek the reasons for the GABA yield difference then effectively elevate lactic acid bacterial GABA production by improving or regulating a strain.

\section{Materials and methods}

\section{Bacterial strain, media and cultivation}

Lactobacillus brevis CD0817 (=CCTCCM2018462) was isolated from a fecal sample of a healthy adult (Chen et al. 2019). The seed medium ( $\mathrm{pH}$ 5.0) contained $(\mathrm{g} / \mathrm{L})$ : glucose, 50 ; yeast extract, 25 ; monosodium L-glutamate, 28; manganese sulfate, 0.01 ; and Tween-80, 2. The fermentation medium was $(\mathrm{g} / \mathrm{L})$ : glucose, 25; yeast extract, 25; L-glutamic acid, 515; manganese sulfate, 0.025; and Tween-80, 2. Glucose, L-glutamic acid, and the other components of the fermentation medium were separately autoclaved at $121{ }^{\circ} \mathrm{C}$ for $30 \mathrm{~min}$ and mixed together prior to inoculation. The L. brevis CD0817 cells were incubated in the seed medium at $32{ }^{\circ} \mathrm{C}$ and $100 \mathrm{rpm}$ for $5-10 \mathrm{~h}$ till the absorbance at $600 \mathrm{~nm}$ reached $4.0-6.0$ and then could be used as inoculum. Ten $\mathrm{mL}$ the seed was transferred into a $250-\mathrm{mL}$ flask containing $100 \mathrm{~mL}$ the fermentation medium then statically incubated at $32{ }^{\circ} \mathrm{C}$ for $60 \mathrm{~h}$. The GABA concentrations in the fermentation broths were determined by a previously described HPLC method (Li et al. 2009).

\section{Genome sequencing and assembly}

Genomic DNA was extracted from CD0817 cells using TIANamp Bacteria DNA Kit (Tiangen Biotech, Beijing, China) according to the standard protocol as recommended by the manufacturer. Total DNA obtained was subjected to quality control by $1 \%$ agarose gel electrophoresis, and the final concentration was determined by Qubit 2.0 Fluorometer (Life Technology, USA). The genome was sequenced with MPS (massively parallel sequencing) Illumina technology. Three DNA libraries were constructed: one paired-end (PE) library with an insert size of $500 \mathrm{bp}$; two mate-pair (MP) libraries with insert sizes of $2 \mathrm{~kb}$ and $5 \mathrm{~kb}$, respectively. The PE and MP libraries were sequenced using Illumina Miseq platform by PE250 strategy and Illumina HiSeq 2500 platform by PE125 strategy, respectively. Library construction and sequencing were performed at Novogene Bioinformatics Technology Co., Ltd (Beijing, China). Quality control of both PE and MP reads was performed using in-house program. After this step, Illumina PCR adapter reads and low-quality reads were filtered. The filtered reads were de novo assembled by SOAPdenovo (Li et al. 2010; Luo et al. 2012) (http://soap.genomics.org.cn/soapdenovo.html) to generate scaffolds. All reads were used for further gap closure.

\section{Genome component prediction}

A program of tRNAscan-SE (Lowe and Eddy 1997) was used to predict tRNA genes. rRNA genes were identified with rRNAmmer (Lagesen et al. 2007) and sRNAs were predicted by BLAST against Rfam (Nawrocki et al. 2015) database. Repetitive sequences were predicted using RepeatMasker (Saha et al. 2008) (http://www.repeatmask er.org/). Tandem repeats were analyzed using Tandem Repeat Finder (Benson 1999) (http://tandem.bu.edu/trf/ trf.html). Genomic islands were predicted by IslandPathDIOMB (Hsiao et al. 2003). PHASTER (Arndt et al. 2016) (http://phaster.ca/) and CRISPRFinder (Grissa et al. 2007) were used to predict prophages and clustered regularly interspaced short palindromic repeats (CRISPRs), respectively.

\section{Genome annotation}

Protein-coding gene prediction was performed on CD0817 genome assembly by GeneMarkS (Besemer et al. 2001) (http://topaz.gatech.edu/) with integrated model combining the GeneMarkS generated (native) and Heuristic model parameters. A whole genome Blast search (E-value less than $1 \mathrm{e}-5$, minimal alignment length percentage larger than 40\%) (Altschul et al. 1990) was performed against the following 6 databases: COG (Clusters of Orthologous Groups) (Tatusov et al. 1997), GO (Gene Ontology) (Ashburner et al. 2000), KEGG (Kyoto Encyclopedia of Genes and Genomes) (Kanehisa et al. 2006), Swiss-Prot, NR (Non-Redundant Protein Database), and TrEMBL (Magrane and UniProt 2011). Genome overview was created by Circos (Krzywinski et al. 2009) to show annotation information.

\section{Comparative genomic and phylogenetic analyses}

The genomic features and GABA yields of CD0817 and 27 reference lactobacilli strains used in this study are listed in Table 1. Core/Pan genes of CD0817 and the 15 completely sequenced $L$. brevis strains were clustered 
Table 1 Genomic features and GABA yields of the lactobacilli strains used in this study

\begin{tabular}{|c|c|c|c|c|c|c|c|}
\hline Lactobacilli strains & Size (Mb) & GC content (\%) & $\begin{array}{l}\text { No. } \\
\text { of protein- } \\
\text { coding gene }\end{array}$ & No. of plasmid & $\begin{array}{l}\text { GenBank/ } \\
\text { RefSeq accession } \\
\text { number }\end{array}$ & GABA yield (g/L) & References \\
\hline L. brevis CD0817 & 3.10 & 50.35 & 2990 & 4 & СР032931.1 & 252 & This study \\
\hline L. brevis ATCC 367 & 2.34 & 46.04 & 2180 & 2 & NC_008497.1 & NA & Makarova et al. (2006) \\
\hline L. brevis KB290 & 2.59 & 45.57 & 2457 & 9 & NC_020819.1 & NA & Fukao et al. (2013) \\
\hline L. brevis NPS-QW-145 & 2.55 & 45.80 & 2391 & 0 & NZ_CP015398.1 & 25.83 & Wu et al. (2015) \\
\hline L. brevis TMW 1.2112 & 2.67 & 45.72 & 2338 & 5 & NZ_CP016797.1 & NA & Fraunhofer et al. (2018) \\
\hline L. brevis TMW 1.2113 & 2.67 & 45.70 & 2321 & 4 & NZ_CP019750.1 & NA & NA \\
\hline L. brevis TMW 1.2108 & 2.92 & 45.27 & 2738 & 8 & NZ_CP019734.1 & NA & NA \\
\hline L. brevis TMW 1.2111 & 2.88 & 45.31 & 2508 & 6 & NZ_CP019743.1 & NA & NA \\
\hline L. brevis 100D8 & 2.48 & 45.75 & 2355 & 3 & NZ_CP015338.1 & NA & NA \\
\hline L. brevis SRCM101174 & 2.57 & 45.59 & 2474 & 5 & NZ_CP021478.1 & NA & NA \\
\hline L. brevis SRCM101106 & 2.55 & 45.60 & 2421 & 4 & NZ_CP021672.1 & NA & NA \\
\hline L. brevis BDGP6 & 2.79 & 45.60 & 2679 & 0 & NZ_CP024635.1 & NA & NA \\
\hline L. brevis ZLB004 & 2.66 & 45.61 & 2420 & 5 & NZ_CP021456.1 & NA & NA \\
\hline L. brevis LMT1-73 & 2.53 & 45.89 & 2347 & 2 & NZ_CP033885.1 & NA & NA \\
\hline L. brevis NCTC13768 & 2.49 & 46.00 & 2356 & 0 & NZ_LS483405.1 & NA & NA \\
\hline L. brevis BSO 464 & 2.72 & 45.46 & 2606 & 8 & СР005977.1 & NA & $\begin{array}{l}\text { Bergsveinson et al. } \\
\text { (2015) }\end{array}$ \\
\hline L. brevis CGMCC 1306 & NA & NA & NA & NA & NA & 76.36 & Fan et al. (2012) \\
\hline L. brevis HYE1 & NA & NA & NA & NA & NA & 1.93 & Lim et al. (2017) \\
\hline L. brevis $877 \mathrm{G}$ & NA & NA & NA & NA & NA & 1.91 & Seo et al. (2013) \\
\hline L. brevis IFO 12005 & NA & NA & NA & NA & NA & 1.05 & Yokoyama et al. (2002) \\
\hline L. brevis OPK-3 & NA & NA & NA & NA & NA & 2.02 & Park and Oh (2007) \\
\hline $\begin{array}{l}\text { L. paracasei NFRI } \\
7415\end{array}$ & NA & NA & NA & NA & NA & 31.14 & $\begin{array}{l}\text { Komatsuzaki et al. } \\
(2008)\end{array}$ \\
\hline L. plantrarum WCFS1 & 3.35 & 44.45 & 3063 & 3 & NC_004567.2 & NA & $\begin{array}{l}\text { Kleerebezem et al. } \\
\text { (2003) }\end{array}$ \\
\hline $\begin{array}{l}\text { L. paraplantarum } \\
\text { L-ZS9 }\end{array}$ & 3.14 & 44.00 & 2835 & 0 & NZ_CP013130.1 & NA & Liu and Li (2016) \\
\hline L. reuteriTD1 & 2.15 & 38.80 & 1890 & 0 & NC_021872.1 & NA & Leonard et al. (2014) \\
\hline L. fermentum F-6 & 2.06 & 51.70 & 1874 & 0 & NC_021235.1 & NA & Sun et al. (2015b) \\
\hline $\begin{array}{l}\text { L. buchneri NRRL } \\
\text { B-30929 }\end{array}$ & 2.59 & 44.21 & 2368 & 3 & NC_015420.1 & NA & Liu et al. (2011) \\
\hline L. oris J-1 & 3.24 & 51.36 & 2868 & 2 & СР014787.1 & NA & NA \\
\hline
\end{tabular}

NA: not available; the CD0817 and 15 completely sequenced Lactobacillus brevis strains were selected for comparative genomics analysis; all lactobacilli strains listed in the table were selected for GAD analysis

by the Cd-hit ( $\mathrm{Li}$ and Godzik 2006) software with a threshold of $50 \%$ pairwise identity and 0.7 length difference cutoff in amino acid. Gene family was constructed with the protein-coding genes of CD0817 and the $15 \mathrm{~L}$. brevis strains, using multi softwares: Blast (Altschul et al. 1990) was used to pairwise align all protein-coding genes and the redundancy was eliminated by Solar and gene family clustering treatment for the alignment results was carried out with Hcluster_sg software. The phylogenetic trees were respectively constructed for the GAD genes retrieved from the 28 lactobacilli strains and the 718 single-copy orthologous genes detected from the gene family analysis across 16 completely sequenced L. brevis strains by the TreeBeST (Nandi et al. 2010) using the method of PhyML with 1000 replications. Synteny analysis between CD0817 and NPS-QW-145 (Wu et al. 2015) was performed using MUMmer (Kurtz et al. 2004) and LASTZ (Chiaromonte et al. 2002) alignment tools.

\section{Nucleotide sequence accession number}

The CD0817 complete genome sequence data has been deposited in the GenBank database under the accession 
numbers of CP032931.1 (chromosome), CP032932.1 (pCD0817-1), CP032933.1 (pCD0817-2), CP032934.1 (pCD0817-3), and CP032935.1 (pCD0817-4).

\section{Results}

General genomic features of $L$. brevis CD0817

The principal features of CD0817 genome are visualized in Fig. 1. The genome comprises one 2,990,570-bp circular chromosome with an average GC content of 50.63\%

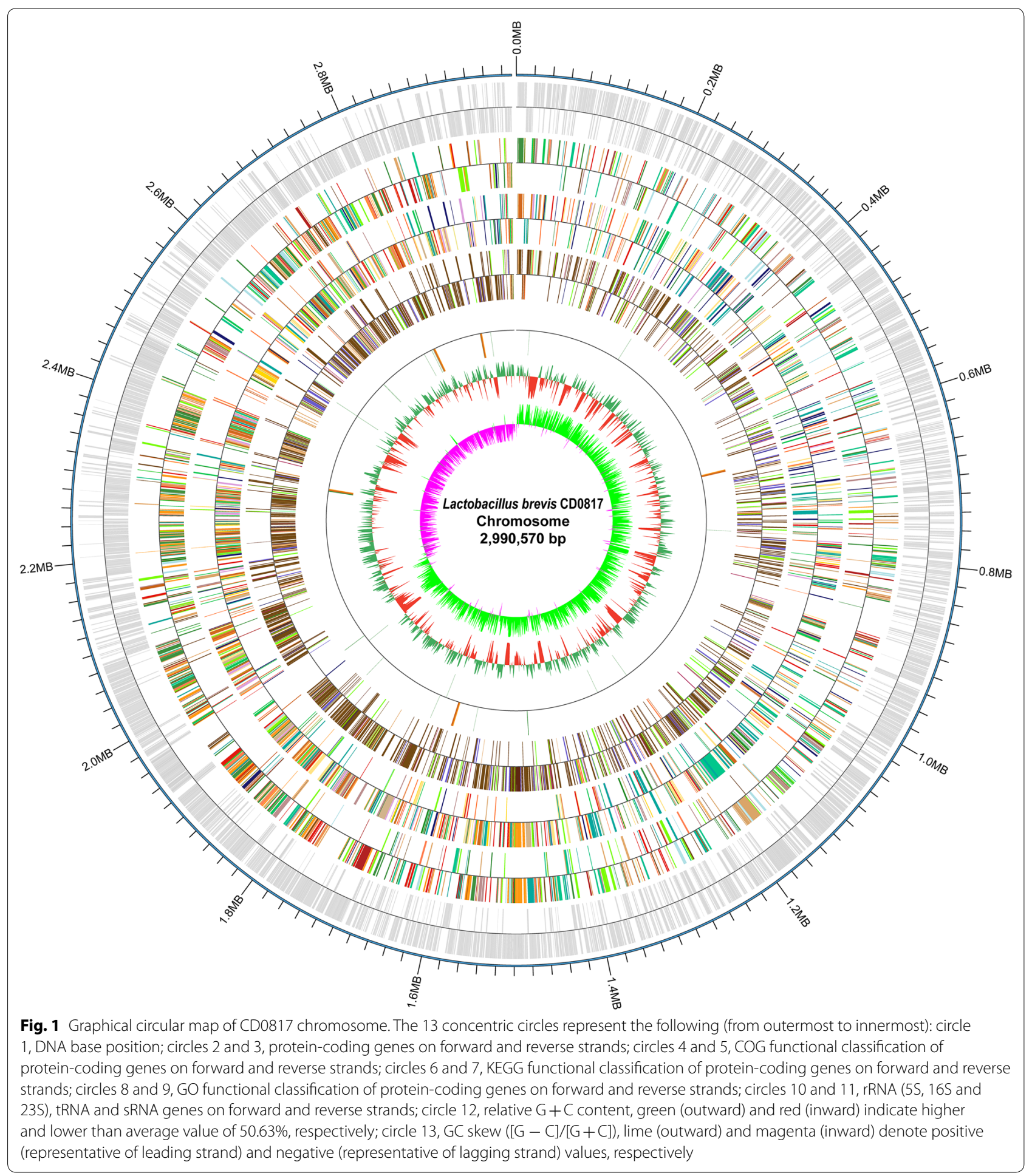




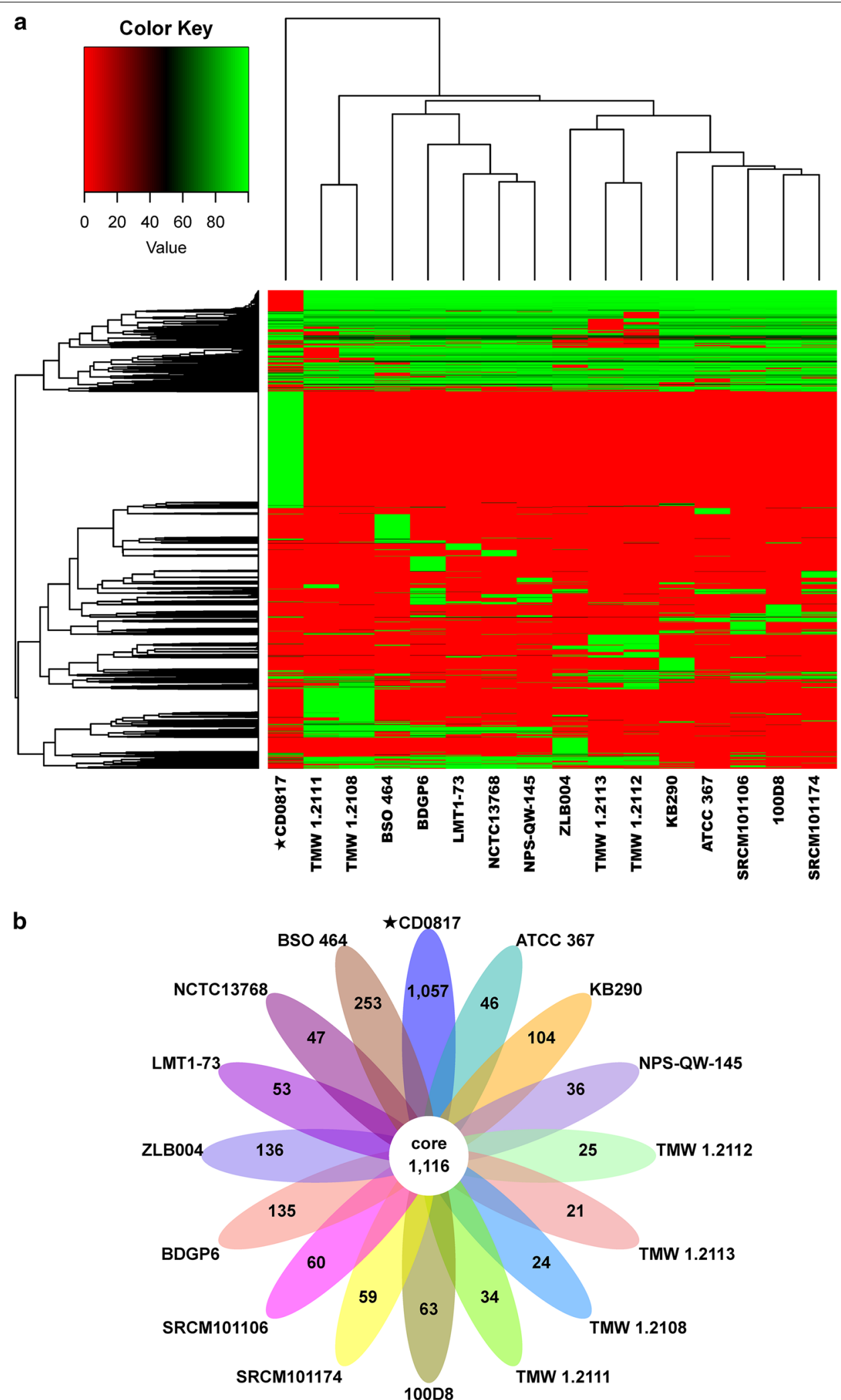

Fig. 2 Core/Pan gene analysis of CD0817 and 15 completely sequenced reference Lactobacillus brevis strains. a Heatmap with the deletion of core gene. $\mathbf{b}$ Venn diagram of core and specific genes in each strain 

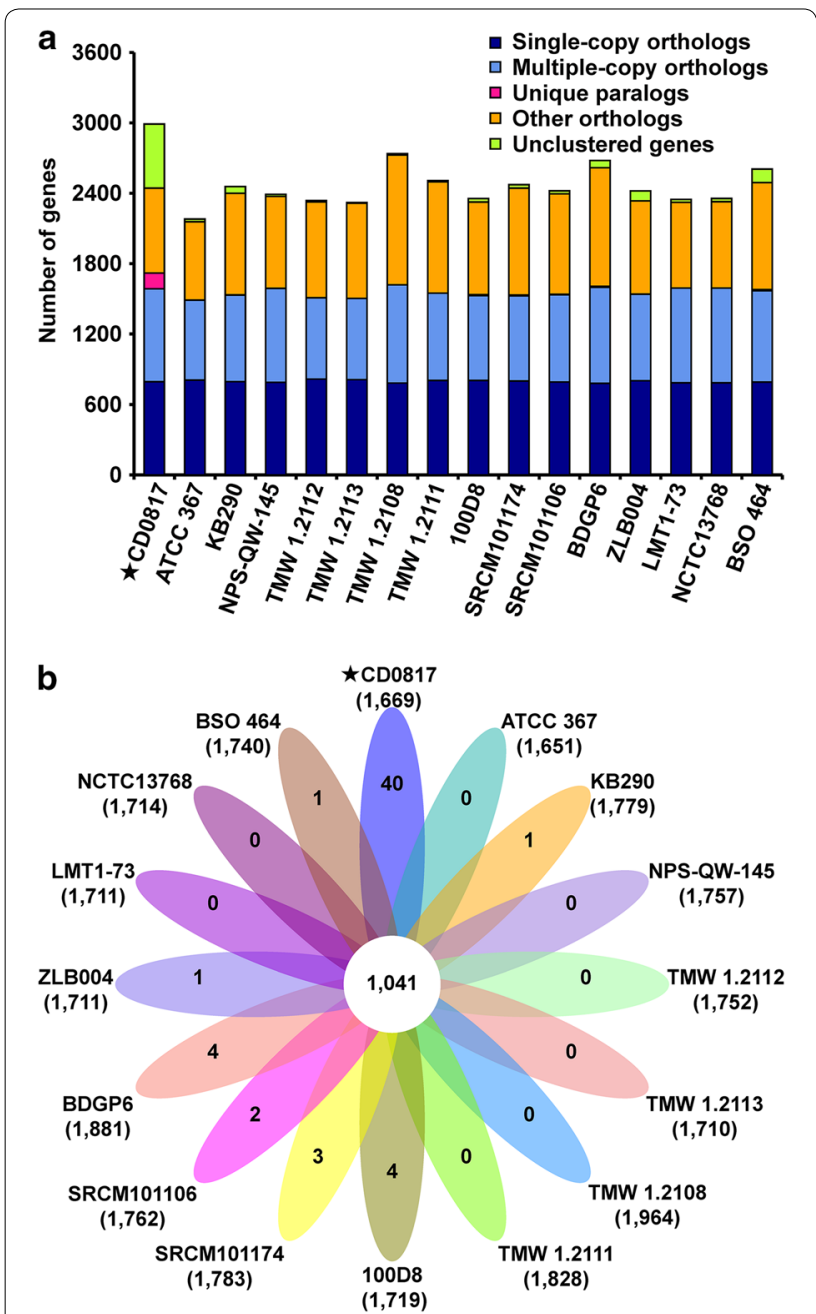

Fig. 3 Gene family analysis of CD0817 and 15 completely sequenced reference Lactobacillus brevis strains. a Barchart of ortholog and paralog in each strain. $\mathbf{b}$ Venn diagram of shared and unique families in each strain. Number in the center of diagram indicates shared families. Numbers in outer end of ellipse indicate unique families. Numbers under strain names indicate total families

and four distinct plasmids designated as pCD0817-1 (37,310 bp), pCD0817-2 (30,761 bp), pCD0817-3 (26,298 bp), and pCD0817-4 (11,935 bp) with mean GC contents of $39.73 \%, 40.53 \%, 41.16 \%$, and $57.47 \%$, respectively. A total of 2990 protein-coding genes, 16 rRNA genes (four 16S-23S-5S operons and one 16S-23S-5S$5 \mathrm{~S}$ operon), 51 tRNA genes, 3 sRNAs, 214 interspersed repeated sequences, 106 tandem repeats, 80 minisatellite DNAs, 1 microsatellite DNAs, 8 genomic islands, 2 prophages, and 6 credible CRISPR loci were predicted in the chromosome. All the rRNA loci and predominant transcription of the protein-coding genes are in phase with the direction of DNA replication.

\section{Genome annotation}

Total 1290 protein-coding genes in L. brevis CD0817 were assigned to $20 \mathrm{COG}$ functional categories. The top four classes are: general function prediction only (190, 14.7\%); translation, ribosomal structure and biogenesis (138, 10.7\%); replication, recombination and repair (128, 9.9\%); and amino acid transport and metabolism (127, 9.8\%). The protein-coding genes involved in cell motility $(2,0.16 \%)$ represented the smallest group (Additional file 1: Fig. S1).

According to GO database, 1556 protein-coding genes belonging to three major categories of molecular function, cellular component and biological process were categorized into 35 subcategories (Additional file 1: Fig. S2). In the 9 subcategories of molecular function category, a majority of the genes were classified into catalytic and binding subcategories. Most genes were grouped into cell part and cell among the 7 subcategories of cellular component category. Within the 19 subcategories of biological process category, most genes were assigned to metabolic process and cellular process.

Altogether 1407 protein-coding genes were presumed to participate in 30 KEGG pathways (Additional file 1: Fig. S3). The largest category was membrane transport $(275,19.5 \%)$, followed by replication and repair (213, $15.1 \%)$, carbohydrate metabolism $(199,14.1 \%)$, and translation $(174,12.4 \%)$.

2563, 1030, and 2459 of the predicted 2990 proteins were classified into NR, Swiss-Prot, and TrEMBL functional categories, respectively.

\section{Comparative genomic analysis}

To investigate the features that are present in CD0817, a comparative genomic analysis against 15 completely sequenced L. brevis strains was performed. Core/ Pan gene analysis provided a core genome set of 1116 orthologs complemented by a dispensable genome set of 4250 genes, resulting in a pan-genome of 5366 genes. The number of core genes decreased while pan genes increased with the number of added strains (Additional file 1: Figs. S4 and S5). The heatmap after core gene deletion showed that CD0817 formed a distinct branch from the reference L. brevis strains, based on their gene contents (Fig. 2a). CD0817 had 1057 strain-specific genes (Fig. 2b).

Gene family analysis revealed that total 2566 gene families were obtained among the 16 strains. Focusing on strain CD0817, 2444 genes were grouped into 1669 families with 40 of which were unique (Fig. 3).

The gene synteny across the whole genomes of both L. brevis CD0817 and L. brevis NPS-QW-145 showed many gene translocation, inversion, and translocation 


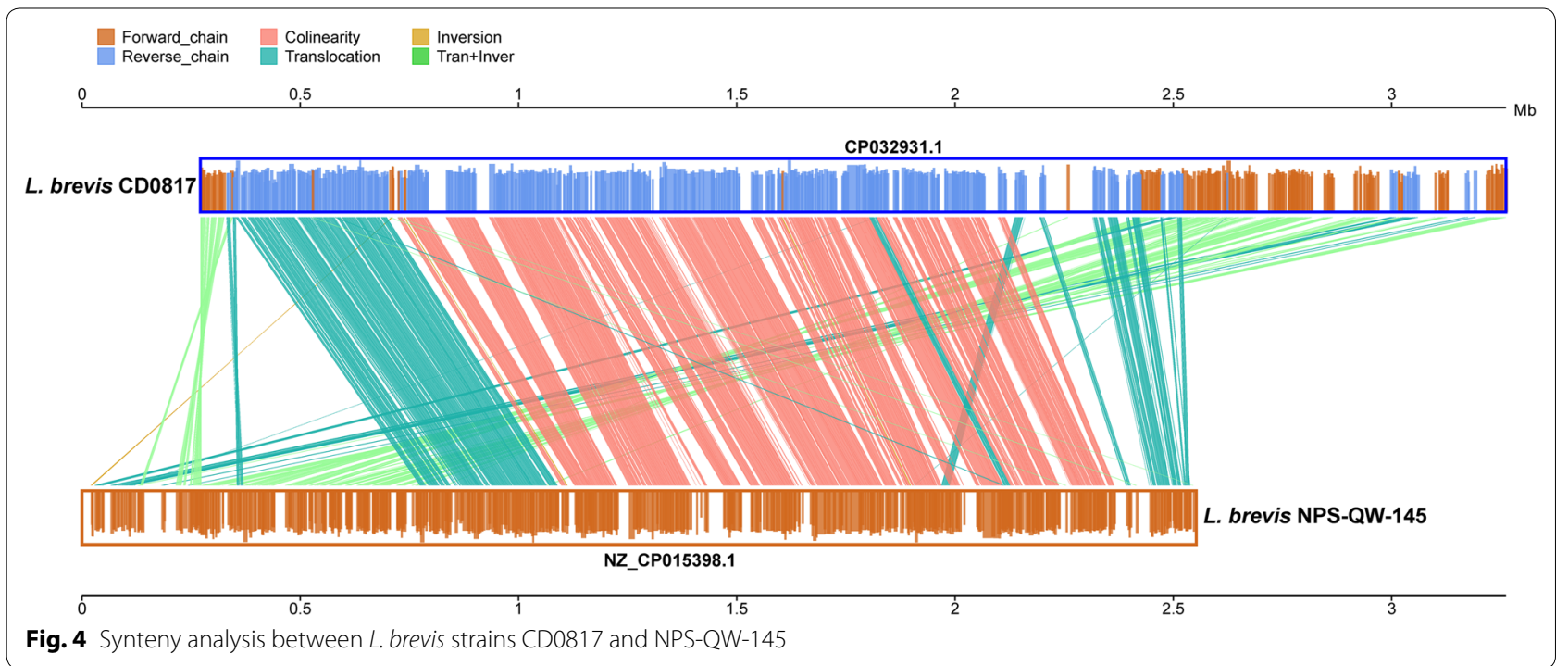

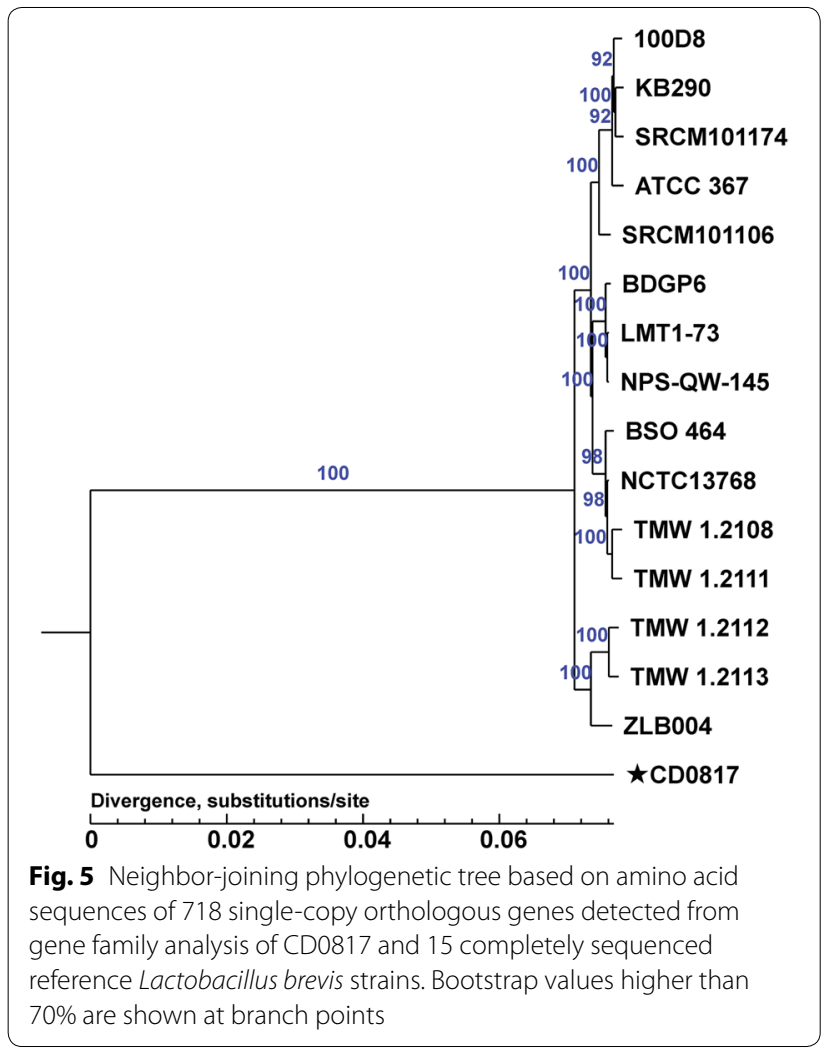

plus inversion events occurred between these two strains (Fig. 4).

\section{Phylogenetic analysis}

A neighbor-joining tree based on 718 single-copy orthologous genes detected from gene family analysis was constructed with 1000 replications in the bootstrap test. The phylogenetic tree shows that CD0817 diverged from other L. brevis strains in evolutionary process (Fig. 5).

\section{GAD genes}

To investigate lactobacilli GAD genes, a maximum-likelihood tree was constructed with 1000 replications in the bootstrap test (Fig. 6a). The phylogenetic tree shows that there are two GAD genes termed $\operatorname{gadA}(\sim 479$ aa) and $\operatorname{gadB}(\sim 468 \mathrm{aa})$ in the low GABA-producing L. brevis genomes. However, gadB is absent from L. brevis CD0817 genome (Fig. 6b). Moreover, the GAD in CD0817 exhibits obvious difference from those in the other low GABAproducing $L$. brevis strains, as the amino acid sequence identity values of $\operatorname{gadA}$ and $\operatorname{gadC}$ in CD0817 against those in the other L. brevis strains are only $91 \%$ (Additional file 1: Fig. S6) and 90\% (Additional file 1: Fig. S7), respectively.

\section{Discussion}

Recently, we screened intestinal L. brevis CD0817, a strongest GABA-producing LAB strain (Chen et al. 2019). To facilitate elucidating its high yield molecular mechanism in the future research, we sequenced the genome of CD0817 in this work. CD0817 harbors a larger genome (3.10 Mb versus $2.34-2.92 \mathrm{Mb}$ ) with higher GC content (50.35\% versus $45.27-46.04 \%)$ and more proteincoding genes (2990 versus $2180-2738)$ than the other completely sequenced $L$. brevis strains (Table 1 ).

COG is a database of proteins in which gene products are generally classified into dissimilar clusters of orthologous groups according to their homologous relationships (Tatusov et al. 1997). A total of 1290 L. brevis 
a

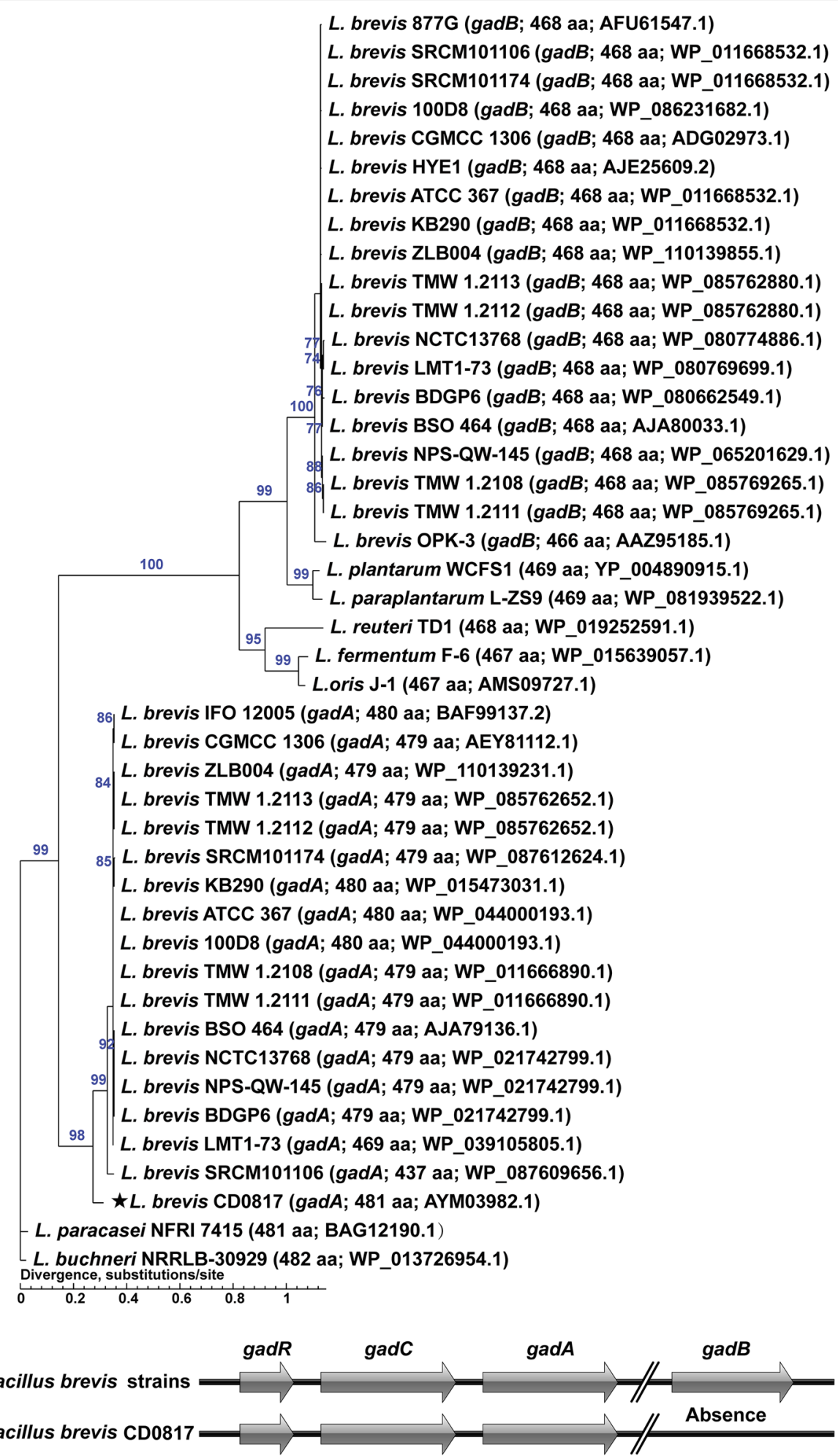

Fig. 6 GAD analysis of CD0817 and 27 reference lactobacilli strains. a The maximum-likelihood tree based on amino acid sequences of GAD genes. Bootstrap values higher than $70 \%$ are shown at branch points. The length and GenBank accession numbers of GAD genes from each strain are shown in brackets. $\mathbf{b}$ Arrangements of GAD genes from CD0817 or other completely sequenced Lactobacillus brevis strains. gadR, transcriptional regulator gene; gadC, glutamate/GABA antiporter gene; gadA/gadB, GAD genes 
CD0817 protein-coding genes were assigned to 20 COG functional categories. The top four classes (general function prediction only; translation, ribosomal structure and biogenesis; replication, recombination and repair; and amino acid transport and metabolism) (Additional file 1: Fig. S1) were approximately consistent with those features in LAB (Barrangou et al. 2009; Makarova et al. 2006; Makarova and Koonin 2007).

Core genes were reduced while pan genes were increased with increasing strains (Additional file 1: Figs. S4 and S5), implying that the L. brevis strains analyzed harbor an open pan-genome ( $\mathrm{Li}$ et al. 2014; Sun et al. 2015a). CD0817 possesses much more strain-specific genes than other $L$. brevis strains (1057 versus 21-253) (Fig. 2b). Whether these specific genes contribute to the high GABA production of CD0817 deserves further work. The whole genomic structures between $L$. brevis CD0817 and NPS-QW-145 were not very conserved, partially attributed to a lot of gene translocation, inversion, and translocation plus inversion events (Fig. 4).

The low GABA-producing L. brevis strains have an identical GAD system consisting of $\operatorname{gadCA}$ and $\operatorname{gadB}$ (Lyu et al. 2018; Shi and Li 2011; Wu et al. 2015; Zhang et al. 2010); however, these L. brevis strains showed various GABA-producing abilities. Clearly, the GAD system alone may be not sufficient to explicate the molecular basis for this difference in GABA production, implying that the generation of GABA may also be associated with complex cell physiology essentially ascribed to a genome (Lyu et al. 2017).

More interestingly, L. brevis CD0817 only containing gadCA (Fig. 6b) exhibited hitherto the most powerful lactic acid bacterial GABA production potential (Lyu et al. 2018; Wu and Shah 2015; Zhao et al. 2015). Although the exact molecular mechanism underlying the robust GABA formation ability by this "defective" GAD system in L. brevis CD0817 has yet to be elucidated, Lyu et al. (2018) recently verified in L. brevis CGMCC1306 that the gadCA operon was the major contributor to GABA production while the contribution of $\operatorname{gadB}$ was marginal, suggesting that $\operatorname{gadCA}$ operon rather than $\operatorname{gadB}$ was responsible for extracellular GABA accumulation (Wu et al. 2017). Therefore, the lack of $\operatorname{gadB}$ in CD0817 may not have a negative impact on the GABA synthesis. The extraordinary genome with a distinct GAD system $(\operatorname{gad} C A)$ may endow CD0817 with a unique cell physiological state conducive to GABA production.

In conclusion, the distinctive genome of a powerful GABA-producer L. brevis CD0817 was provided, followed by the comparative genomic analysis and discussion on this genome against 27 lactobacilli genomes. The generation of GABA may be related to not only GAD system but genome. This work may facilitate our understanding of the molecular mechanisms underlying the difference in lactic acid bacterial GABA-producing ability, thus enhancing GABA production by improving a $\mathrm{LAB}$ strain or metabolic regulation.

\section{Additional file}

\begin{abstract}
Additional file 1: Fig. S1. Distribution of protein-coding genes across COG functional categories in CD0817 genome. Note: one protein-coding gene might be assigned to more than one category. Fig. S2. Distribution of protein-coding genes across GO functional categories in CD0817 genome. Note: one protein-coding gene might be assigned to more than one category. Fig. S3. Distribution of protein-coding genes across KEGG pathway categories in CD0817 genome. Note: one protein-coding gene might be assigned to more than one category. Fig. S4. Dilution curve of core gene from CD0817 and 15 completely sequenced reference Lactobacillus brevis genomes. Fig. S5. Dilution curve of pan gene from CD0817 and 15 completely sequenced reference Lactobacillus brevis genomes. Fig. S6. Alignment of GadA primary structures of CD0817 and low GABAproducing lactobacilli strains. The amino acid residues in the black box are the conserved motif (HVDAA [S/F] GG); the amino acid in green box are the pyridoxal 5'-phosphate binding domain. Fig. S7. Alignment of GadC primary structures of CD0817 and low GABA-producing lactobacilli strains.
\end{abstract}

\section{Abbreviations}

L. brevis: Lactobacillus brevis; GABA: gamma-aminobutyric acid; LAB: lactic acid bacteria; GAD: glutamic acid decarboxylase; COG: clusters of orthologous groups; GO: gene ontology; KEGG: kyoto encyclopedia of genes and genomes; NR: non-redundant protein database.

\section{Acknowledgements}

Not applicable.

\section{Authors' contributions}

The initiative for this work was from HL. HL, KC and DG designed experiments. $D G$ and $K C$ did genome component prediction and genome annotation. GD, HW, YC, MJ, XL and SW did the comparative genomic and phylogenetic analysis. YJ and HP prepared the media, cultured the strain and isolated the genomic DNA. KC and HL wrote the manuscript. All authors read and approved the final manuscript.

\section{Funding}

This work was supported by the National Natural Science Foundation of China (Grant Numbers 31570070 and 21566023), the Fundamental Research Funds for the Central Universities of Northwest Minzu University (Grant Number 31920190023), and Jiangxi Provincial Department of Science and Technology (Grant Numbers 20153BCB23034 and 20171BAB204002).

\section{Availability of data and materials}

The datasets supporting the conclusions of this article are included within the article.

\section{Ethics approval and consent to participate}

Not applicable.

\section{Consent for publication}

Not applicable.

\section{Competing interests}

The authors declare that they have no competing interests.

\section{Author details}

${ }^{1}$ Biomedical Research Center, College of Life Sciences and Engineering, Northwest Minzu University, Lanzhou 730030, Gansu, People's Republic of China.

2 State Key Laboratory of Food Science and Technology, Nanchang University, 
Nanchang 330047, Jiangxi, People's Republic of China. ${ }^{3}$ Sino-German Joint Research Institute, Nanchang University, Nanchang 330047, Jiangxi, People's Republic of China. ${ }^{4}$ Nanchang University College of Science and Technology, Nanchang 330029, Jiangxi, People's Republic of China.

Received: 29 January 2019 Accepted: 16 May 2019 Published online: 24 May 2019

\section{References}

Altschul SF, Gish W, Miller W, Myers EW, Lipman DJ (1990) Basic local alignment search tool. J Mol Biol 215(3):403-410. https://doi.org/10.1016/S0022 $-2836(05) 80360-2$

Arndt D, Grant JR, Marcu A, Sajed T, Pon A, Liang Y, Wishart DS (2016) PHASTER: a better, faster version of the PHAST phage search tool. Nucleic Acids Res 44(W1):W16-21. https://doi.org/10.1093/nar/gkw387

Ashburner M, Ball CA, Blake JA, Botstein D, Butler H, Cherry JM, Davis AP, Dolinski K, Dwight SS, Eppig JT, Harris MA, Hill DP, Issel-Tarver L, Kasarskis A, Lewis S, Matese JC, Richardson JE, Ringwald M, Rubin GM, Sherlock G (2000) Gene ontology: tool for the unification of biology. The Gene Ontology Consortium. Nat Genet 25(1):25-29. https://doi.org/10.1038/75556

Barrangou R, Briczinski EP, Traeger LL, Loquasto JR, Richards M, Horvath P, Coute-Monvoisin AC, Leyer G, Rendulic S, Steele JL, Broadbent JR, Oberg T, Dudley EG, Schuster S, Romero DA, Roberts RF (2009) Comparison of the complete genome sequences of Bifidobacterium animalis subsp. lactis DSM 10140 and BI-04. J Bacteriol 191(13):4144-4151. https://doi. org/10.1128/jb.00155-09

Benson G (1999) Tandem repeats finder: a program to analyze DNA sequences. Nucleic Acids Res 27(2):573-580. https://doi.org/10.1093/nar/27.2.573

Bergsveinson J, Pittet V, Ewen E, Baecker N, Ziola B (2015) Genome sequence of rapid beer-spoiling isolate Lactobacillus brevis BSO 464. Genome Announc. https://doi.org/10.1128/genomea.01411-15

Besemer J, Lomsadze A, Borodovsky M (2001) GeneMarkS: a self-training method for prediction of gene starts in microbial genomes. Implications for finding sequence motifs in regulatory regions. Nucleic Acids Res 29(12):2607-2618. https://doi.org/10.1093/nar/29.12.2607

Chen Y, Chang K, Xie X, Liu X, Jia M, Nie L, Li H, Wang S (2019) Disassociation of glutamate from $\gamma$-aminobutyric acid by zinc acetate-assisted differential precipitation/dissolution: application to the quantification of $\mathrm{Y}$-aminobutyric acid. J Chromatogr A 1590:19-26. https://doi. org/10.1016/j.chroma.2019.01.002

Chiaromonte F, Yap VB, Miller W (2002) Scoring pairwise genomic sequence alignments. In: Pac Symp Biocomput, pp 115-126

Fan E, Huang J, Hu S, Mei L, Yu K (2012) Cloning, sequencing and expression of a glutamate decarboxylase gene from the GABA-producing strain Lactobacillus brevis CGMCC 1306. Ann Microbiol 62(2):689-698. https:// doi.org/10.1007/s13213-011-0307-5

Fraunhofer ME, Geissler AJ, Wefers D, Bunzel M, Jakob F, Vogel RF (2018) Characterization of beta-glucan formation by Lactobacillus brevis TMW 1.2112 isolated from slimy spoiled beer. Int J Biol Macromol 107(Pt A):874-881. https://doi.org/10.1016/j.ijbiomac.2017.09.063

Fukao M, Oshima K, Morita H, Toh H, Suda W, Kim SW, Suzuki S, Yakabe T, Hattori M, Yajima N (2013) Genomic analysis by deep sequencing of the probiotic Lactobacillus brevis KB290 harboring nine plasmids reveals genomic stability. PLoS ONE 8(3):e60521. https://doi.org/10.1371/journ al.pone.006052

Grissa I, Vergnaud G, Pourcel C (2007) CRISPRFinder: a web tool to identify clustered regularly interspaced short palindromic repeats. Nucleic Acids Res 35(Web Server issue):W52-57. https://doi.org/10.1093/nar/gkm360

Hsiao W, Wan I, Jones SJ, Brinkman FS (2003) IslandPath: aiding detection of genomic islands in prokaryotes. Bioinformatics 19(3):418-420. https://doi. org/10.1093/bioinformatics/btg004

Inoue K, Shirai T, Ochiai H, Kasao M, Hayakawa K, Kimura M, Sansawa H (2003) Blood-pressure-lowering effect of a novel fermented milk containing gamma-aminobutyric acid (GABA) in mild hypertensives. Eur J Clin Nutr 57(3):490-495. https://doi.org/10.1038/sj.ejcn.1601555

Kanehisa M, Goto S, Hattori M, Aoki-Kinoshita KF, Itoh M, Kawashima S, Katayama T, Araki M, Hirakawa M (2006) From genomics to chemical genomics: new developments in KEGG. Nucleic Acids Res 34(Database issue):D354D357. https://doi.org/10.1093/nar/gkj102
Kleerebezem M, Boekhorst J, van Kranenburg R, Molenaar D, Kuipers OP, Leer R, Tarchini R, Peters SA, Sandbrink HM, Fiers MW, Stiekema W, Lankhorst RM, Bron PA, Hoffer SM, Groot MN, Kerkhoven R, de Vries M, Ursing B, de Vos WM, Siezen RJ (2003) Complete genome sequence of Lactobacillus plantarum WCFS1. Proc Natl Acad Sci U S A 100(4):1990-1995. https://doi. org/10.1073/pnas.0337704100

Komatsuzaki N, Shima J, Kawamoto S, Momose H, Kimura T (2005) Production of gamma-aminobutyric acid (GABA) by Lactobacillus paracasei isolated from traditional fermented foods. Food Microbiol 22:497-504

Komatsuzaki N, Nakamura T, Kimura T, Shima J (2008) Characterization of glutamate decarboxylase from a high gamma-aminobutyric acid (GABA)producer, Lactobacillus paracasei. Biosci Biotechnol Biochem 72(2):278285. https://doi.org/10.1271/bbb.70163

Krzywinski M, Schein J, Birol I, Connors J, Gascoyne R, Horsman D, Jones SJ, Marra MA (2009) Circos: an information aesthetic for comparative genomics. Genome Res 19(9):1639-1645. https://doi.org/10.1101/ gr.092759.109

Kurtz S, Phillippy A, Delcher AL, Smoot M, Shumway M, Antonescu C, Salzberg SL (2004) Versatile and open software for comparing large genomes. Genome Biol 5(2):R12. https://doi.org/10.1186/gb-2004-5-2-r12

Lagesen K, Hallin P, Rodland EA, Staerfeldt HH, Rognes T, Ussery DW (2007) RNAmmer: consistent and rapid annotation of ribosomal RNA genes. Nucleic Acids Res 35(9):3100-3108. https://doi.org/10.1093/nar/gkm160

Leonard MT, Valladares RB, Ardissone A, Gonzalez CF, Lorca GL, Triplett EW (2014) Complete genome sequences of Lactobacillus johnsonii strain N6.2 and Lactobacillus reuteri strain TD1. Genome Announc. https://doi. org/10.1128/genomea.00397-14

Li H, Cao Y (2010) Lactic acid bacterial cell factories for gamma-aminobutyric acid. Amino Acids 39(5):1107-1116. https://doi.org/10.1007/s0072 6-010-0582-7

Li W, Godzik A (2006) Cd-hit: a fast program for clustering and comparing large sets of protein or nucleotide sequences. Bioinformatics 22(13):16581659. https://doi.org/10.1093/bioinformatics/btl158

Li H, Qiu T, Cao Y, Yang J, Huang Z (2009) Pre-staining paper chromatography method for quantification of gamma-aminobutyric acid. J Chromatogr A 1216(25):5057-5060. https://doi.org/10.1016/j.chroma.2009.04.044

Li R, Zhu H, Ruan J, Qian W, Fang X, Shi Z, Li Y, Li S, Shan G, Kristiansen K, Li S, Yang H, Wang J, Wang J (2010) De novo assembly of human genomes with massively parallel short read sequencing. Genome Res 20(2):265272. https://doi.org/10.1101/gr.097261.109

Li H, Li W, Liu X, Cao Y (2013) gadA gene locus in Lactobacillus brevis NCL912 and its expression during fed-batch fermentation. FEMS Microbiol Lett 349(2):108-116. https://doi.org/10.1111/1574-6968.12301

Li L, Wong HC, Nong W, Cheung MK, Law PT, Kam KM, Kwan HS (2014) Comparative genomic analysis of clinical and environmental strains provides insight into the pathogenicity and evolution of Vibrio parahaemolyticus. BMC Genomics 15:1135. https://doi.org/10.1186/1471-2164-15-1135

Lim HS, Cha IT, Roh SW, Shin HH, Seo MJ (2017) Enhanced production of gamma-aminobutyric acid by optimizing culture conditions of Lactobacillus brevis HYE1 isolated from kimchi, a Korean fermented food. J Microbiol Biotechnol 27(3):450-459. https://doi.org/10.4014/jmb.1610.10008

Liu L, Li P (2016) Complete genome sequence of Lactobacillus paraplantarum L-ZS9, a probiotic starter producing class II bacteriocins. J Biotechnol 222:15-16. https://doi.org/10.1016/j.jbiotec.2016.02.003

Liu S, Leathers TD, Copeland A, Chertkov O, Goodwin L, Mills DA (2011) Complete genome sequence of Lactobacillus buchneri NRRL B-30929, a novel strain from a commercial ethanol plant. J Bacteriol 193(15):4019-4020. https://doi.org/10.1128/JB.05180-11

Lowe TM, Eddy SR (1997) tRNAscan-SE: a program for improved detection of transfer RNA genes in genomic sequence. Nucleic Acids Res 25(5):955964. https://doi.org/10.1093/nar/25.5.955

Luo R, Liu B, Xie Y, Li Z, Huang W, Yuan J, He G, Chen Y, Pan Q, Liu Y, Tang J, Wu G, Zhang H, Shi Y, Liu Y, Yu C, Wang B, Lu Y, Han C, Cheung DW, Yiu SM, Peng S, Xiaogian Z, Liu G, Liao X, Li Y, Yang H, Wang J, Lam TW, Wang J (2012) SOAPdenovo2: an empirically improved memoryefficient short-read de novo assembler. Gigascience 1(1):18. https://doi. org/10.1186/2047-217X-1-18

Lyu CJ, Zhao WR, Hu S, Huang J, Lu T, Jin ZH, Mei LH, Yao SJ (2017) Physiologyoriented engineering strategy to improve gamma-aminobutyrate production in Lactobacillus brevis. J Agric Food Chem 65(4):858-866. https:// doi.org/10.1021/acs.jafc.6b04442 
Lyu C, Zhao W, Peng C, Hu S, Fang H, Hua Y, Yao S, Huang J, Mei L (2018) Exploring the contributions of two glutamate decarboxylase isozymes in Lactobacillus brevis to acid resistance and $\gamma$-aminobutyric acid production. Microb Cell Fact 17:180

Magrane M, UniProt C (2011) UniProt Knowledgebase: a hub of integrated protein data. Database (Oxford) 2011:bar009. https://doi.org/10.1093/ database/bar009

Makarova KS, Koonin EV (2007) Evolutionary genomics of lactic acid bacteria. J Bacteriol 189(4):1199-1208. https://doi.org/10.1128/JB.01351-06

Makarova K, Slesarev A, WolfY, Sorokin A, Mirkin B, Koonin E, Pavlov A, Pavlova N, Karamychev V, Polouchine N, Shakhova V, Grigoriev I, Lou Y, Rohksa D, Lucas S, Huang K, Goodstein DM, Hawkins T, Plengvidhya V, Welker D, Hughes J, Goh Y, Benson A, Baldwin K, Lee JH, Diaz-Muniz I, Dosti B, Smeianov V, Wechter W, Barabote R, Lorca G, Altermann E, Barrangou R, Ganesan B, Xie Y, Rawsthorne H, Tamir D, Parker C, Breidt F, Broadbent J, Hutkins R, O'Sullivan D, Steele J, Unlu G, Saier M, Klaenhammer T, Richardson P, Kozyavkin S, Weimer B, Mills D (2006) Comparative genomics of the lactic acid bacteria. Proc Natl Acad Sci U S A 103(42):15611-15616. https ://doi.org/10.1073/pnas.0607117103

Nandi T, Ong C, Singh AP, Boddey J, Atkins T, Sarkar-Tyson M, Essex-Lopresti AE, Chua HH, Pearson T, Kreisberg JF, Nilsson C, Ariyaratne P, Ronning C, Losada L, Ruan Y, Sung WK, Woods D, Titball RW, Beacham I, Peak I, Keim P, Nierman WC, Tan P (2010) A genomic survey of positive selection in Burkholderia pseudomallei provides insights into the evolution of accidental virulence. PLoS Pathog 6(4):e1000845. https://doi.org/10.1371/journ al.ppat.1000845

Nawrocki EP, Burge SW, Bateman A, Daub J, Eberhardt RY, Eddy SR, Floden EW, Gardner PP, Jones TA, Tate J, Finn RD (2015) Rfam 12.0: updates to the RNA families database. Nucleic Acids Res 43(Database issue):D130-137. https ://doi.org/10.1093/nar/gku1063

Nikmaram N, Dar BN, Roohinejad S, Koubaa M, Barba FJ, Greiner R, Johnson SK (2017) Recent advances in gamma-aminobutyric acid (GABA) properties in pulses: an overview. J Sci Food Agric 97(9):2681-2689. https://doi. org/10.1002/jsfa.8283

Park KB, Oh SH (2007) Cloning, sequencing and expression of a novel glutamate decarboxylase gene from a newly isolated lactic acid bacterium, Lactobacillus brevis OPK-3. Bioresour Technol 98(2):312-319. https://doi. org/10.1016/j.biortech.2006.01.004

Saha S, Bridges S, Magbanua ZV, Peterson DG (2008) Empirical comparison of ab initio repeat finding programs. Nucleic Acids Res 36(7):2284-2294. https://doi.org/10.1093/nar/gkn064

Seo MJ, Nam YD, Lee SY, Park SL, Yi SH, Lim SI (2013) Expression and characterization of a glutamate decarboxylase from Lactobacillus brevis $877 \mathrm{G}$ producing gamma-aminobutyric acid. Biosci Biotechnol Biochem 77(4):853-856. https://doi.org/10.1271/bbb.120785

Shi F, LiY (2011) Synthesis of gamma-aminobutyric acid by expressing Lactobacillus brevis-derived glutamate decarboxylase in the Corynebacterium glutamicum strain ATCC 13032. Biotechnol Lett 33(12):2469-2474. https:// doi.org/10.1007/s10529-011-0723-4

Siragusa S, De Angelis M, Di Cagno R, Rizzello CG, Coda R, Gobbetti M (2007) Synthesis of gamma-aminobutyric acid by lactic acid bacteria isolated from a variety of Italian cheeses. Appl Environ Microbiol 73(22):72837290. https://doi.org/10.1128/AEM.01064-07

Small PL, Waterman SR (1998) Acid stress, anaerobiosis and gadCB: lessons from Lactococcus lactis and Escherichia coli. Trends Microbiol 6(6):214-216

Sun Z, Harris HM, McCann A, Guo C, Argimon S, Zhang W, Yang X, Jeffery IB, Cooney JC, Kagawa TF, Liu W, Song Y, Salvetti E, Wrobel A, Rasinkangas P, Parkhill J, Rea MC, O'Sullivan O, Ritari J, Douillard FP, Paul Ross R, Yang R, Briner AE, Felis GE, de Vos WM, Barrangou R, Klaenhammer TR, Caufield PW, Cui Y, Zhang H, O'Toole PW (2015a) Expanding the biotechnology potential of lactobacilli through comparative genomics of 213 strains and associated genera. Nat Commun 6:8322. https://doi.org/10.1038/ncomm s9322

Sun Z, Zhang W, Bilige M, Zhang H (2015b) Complete genome sequence of the probiotic Lactobacillus fermentum F-6 isolated from raw milk. J Biotechnol 194:110-111. https://doi.org/10.1016/j.jbiotec.2014.12.010

Tatusov RL, Koonin EV, Lipman DJ (1997) A genomic perspective on protein families. Science 278(5338):631-637. https://doi.org/10.1126/scien ce.278.5338.631

Wong CG, Bottiglieri T, Snead OC 3rd (2003) GABA, gamma-hydroxybutyric acid, and neurological disease. Ann Neurol 54(Suppl 6):S3-12. https://doi. org/10.1002/ana.10696

Wu Q, Shah NP (2015) Gas release-based prescreening combined with reversed-phase HPLC quantitation for efficient selection of high-gammaaminobutyric acid (GABA)-producing lactic acid bacteria. J Dairy Sci 98(2):790-797. https://doi.org/10.3168/jds.2014-8808

Wu Q, Law YS, Shah NP (2015) Dairy Streptococcus thermophilus improves cell viability of Lactobacillus brevis NPS-QW-145 and its gamma-aminobutyric acid biosynthesis ability in milk. Sci Rep 5:12885. https://doi.org/10.1038/ srep12885

Wu Q, Tun HM, Law YS, Khafipour E, Shah NP (2017) Common distribution of gad operon in Lactobacillus brevis and its GadA contributes to efficient GABA synthesis toward cytosolic near-neutral pH. Front Microbiol 8:206. https://doi.org/10.3389/fmicb.2017.00206

Yokoyama S, Hiramatsu J, Hayakawa K (2002) Production of gamma-aminobutyric acid from alcohol distillery lees by Lactobacillus brevis IFO-12005. J Biosci Bioeng 93(1):95-97

Zhang Y, Gao N, Feng Y, Song L, Gao Q (2010) Biotransformation of sodium L-glutamate to $\gamma$-aminobutyric acid by L. brevis TCCC13007 with two glutamate decarboxylase genes. In: 4th International conference on bioinformatics and biomedical engineering https://doi.org/10.1109/ icbbe.2010.5518023

Zhao A, Hu X, Pan L, Wang X (2015) Isolation and characterization of a gammaaminobutyric acid producing strain Lactobacillus buchneri WPZ001 that could efficiently utilize xylose and corncob hydrolysate. Appl Microbiol Biotechnol 99(7):3191-3200. https://doi.org/10.1007/s00253-014-6294-2

\section{Publisher's Note}

Springer Nature remains neutral with regard to jurisdictional claims in published maps and institutional affiliations.

\section{Submit your manuscript to a SpringerOpen ${ }^{\circ}$ journal and benefit from:}

- Convenient online submission

- Rigorous peer review

- Open access: articles freely available online

- High visibility within the field

Retaining the copyright to your article

Submit your next manuscript at springeropen.com 